\title{
Educational intervention in bigger adults with type 2 diabetes mellitus
}

\section{Introduction}

Diabetes Mellitus (DM) is currently considered one of the main health problems worldwide and the socioeconomic impact of this disease in any country is very important. It is estimated that it affects more than 200,000,000 people in the world, it is one of the most expensive to society, due to early mortality, work disability and costs generated by its complications and treatment. Hospitalizations for urgent reasons are 4 times more frequent in diabetics than in the general population. ${ }^{1}$

The impact of Diabetes Mellitus on the world population has caused it to be considered as a health problem, exhibits high rates of morbidity and mortality in both developed and developing countries. The treatment of diabetes is complex, which is why CARE AND EDUCATION must constitute an integral binomial of diabetes services In Cuba, as in other countries of Latin America; diabetes is a health problem that has been increased gradually in recent years. ${ }^{2}$

DM in the elderly is a problem of great importance for health By: Its high prevalence, Difficulties in diagnosis and treatment, Frequency of complications, High mortality and high costs for health care. Aging predisposes to DM and this in turn accelerates aging. The majority of the elderly with diabetes have a Type 2 DM. between 40 and $50 \%$ of Type 2 diabetics are $>65$ years old. It affects more to the feminine sex $(60-70 \%)$ The life expectancy is superior to the 10 years.

Aging is a general term that can be defined in relation to physiological, behavioural, sociological and chronological phenomena. From the medical point of view it is considered as the decline of the physiological capacity and functions on which the social and behavioural factors act. ${ }^{3}$

$\mathrm{DM}$ is one of the most important diseases of the elderly population. It is known that the incidence of DM increases with age, and that there is a progressive increase in the aging rates of the population, so that over time they will find themselves more elderly and more diabetic.

The education of people suffering from diabetes mellitus is essential for them to achieve a long life and with the necessary quality, but it is also important that they have the will to assume the habit changes in their lifestyle. ${ }^{4}$

Throughout the history of humanity, self-care, that is, the treatment of the signs and symptoms of illness that people suffer, has been the most used way to maintain health.

Health professionals face a difficult task that is to educate. Success will only be achieved if all those involved in caring for people with diabetes recognize the need for the educational component, and assume some forms of learning and training in educational methods. ${ }^{5}$

The nurse instructs and guides the person to carry out the necessary self-care. The patient is able to learn and make the necessary decisions for their self-care, since they do not have great limitations or disabilities; they only need support, guidance and teaching. The nursing staffs have always been considered an educator par excellence and the patient must receive a quality health education, based on a

\author{
Volume 3 Issue 3 - 2018
}

\author{
Esther Catalá Sardiñas,' Ania Albanes \\ García,' Irelys Sardiñas Díaz, ${ }^{2}$ Pedro Antono \\ Pinillos Viera ${ }^{3}$ \\ 'Bachelor of Nursing, Facultad de Ciencias médicas de Matanzas, \\ Cuba \\ ${ }^{2}$ Specialist in MGI and Endocrinology, Diabetic Care Center, \\ Cuba \\ ${ }^{3}$ Bachelor of Immanence, Specialist in special studies at Hospital \\ Mario Muñoz de Colón, Cuba
}

Correspondence: Esther Catalá Sardiñas, Facultad de Ciencias médicas de Matanzas, Rafael Águila 150 entre Martha Abreu y Mariana Granjéales, Colón .Matanzas, Cuba. Tel +5352478460 , Email esthercatala.mtz@infomed.sld.cu

Received: April 20, 2018| Published: May 07, 2018

solid base of nursing knowledge.

Given the incidence of elderly diabetic patients who attend the daytime admission regimen at the Diabetic Care Center the author has been motivated to carry out this research with the objective of knowing the level of information that elderly people with type 2 and diabetes have. The effectiveness of an educational intervention as the basis of the model for the comprehensive care of the diabetic, establishing the epidemiological and socio-demographic clinical aspects related to DM.

\section{Material and methods}

A cross - sectional descriptive study is part of a nursing intervention with the aim conocer the level of information that adult's older diabetics day type 2, mo strar the effectiveness of an educational intervention what are you about learning took place and adequate training for diabetic patients. Older adults type 2 treated at the Diabetic Care Center (CAD) in the Municipality of Colón, Matanzas Province from February to December of 2017

Universe: Consisting of 20 diabetic elderly patients who attended the daytime admission regimen in the CAD.

Sample: the same was established by the application of simple random sampling, which will be subject to inclusion criteria, expecting to obtain a self-weighted sample of 20 patients.

\section{Inclusion criteria}

All patients 60 years and older

i. Type 2 diabetic patients.

ii. That the patients express their consent in writing for their participation in the training

iii. Patients treated at the Diabetic center of Attention (CAD) of the municipality of Colón. 


\section{Instruments}

Prior to the beginning of the application of the same the informed consent of each patient in particular was obtained (Annex 1) then a questionnaire was applied which was validated by the Endocrinology Specialist of the diabetic center and the nursing staff that there work with the objective of determining the level of information that had the adult Mayortes diabeticos. (Annex 2) they underwent glycaemia to know the metabolic control they had before carrying out the research, an educational program was carried out that was given to the patient $\mathrm{s}$ as shown in (Annex 3) (Table 1).

Table I The variables were captured in a statistical model prepared for this purpose and selected previously being operationalized and coded as follows

\begin{tabular}{|c|c|c|c|}
\hline Variable & $\begin{array}{l}\text { Type of } \\
\text { variable }\end{array}$ & operationalization & Conceptual definition of the variables \\
\hline Age & $\begin{array}{l}\text { Qualitative } \\
\text { Politics } \\
\text { keep going }\end{array}$ & $\begin{array}{l}60-65 \\
66-70 \\
71 \text { and more }\end{array}$ & $\begin{array}{l}\text { The biological age will be measured in years } \\
\text { completed. }\end{array}$ \\
\hline Sex & $\begin{array}{l}\text { Qualitative } \\
\text { Dichotomous }\end{array}$ & $\begin{array}{l}\text { Female } \\
\text { Male }\end{array}$ & Generic \\
\hline $\begin{array}{l}\text { Degree of } \\
\text { metabolic } \\
\text { control }\end{array}$ & $\begin{array}{l}\text { Qualitative } \\
\text { nominal } \\
\text { Politics }\end{array}$ & $\begin{array}{l}\text { Suitable } \\
\text { Admissible } \\
\text { Inadequate }\end{array}$ & $\begin{array}{l}5-8 \\
8-9 \\
10+\end{array}$ \\
\hline $\begin{array}{l}\text { Time of } \\
\text { evolution }\end{array}$ & $\begin{array}{l}\text { Quantitative } \\
\text { nominal } \\
\text { Politics }\end{array}$ & $\begin{array}{l}-1 \text { year } \\
1-5 \\
6-9 \\
10 \text { and more }\end{array}$ & $\begin{array}{l}\text { Diagnosed by attending physician and } \\
\text { complementary exams }\end{array}$ \\
\hline Risk factor's & $\begin{array}{l}\text { Qualitative } \\
\text { nominal } \\
\text { Politics }\end{array}$ & $\begin{array}{l}\text { Arterial hypertension } \\
\text { Obesity. Overweight. } \\
\text { Bad perforating plant, sedentary lifestyle, } \\
\text { smokers, ingestion of alcoholic beverages }\end{array}$ & $\begin{array}{l}\text { Diagnosed by attending physician and } \\
\text { complementary exams }\end{array}$ \\
\hline $\begin{array}{l}\text { Knowledge } \\
\text { about diabetes }\end{array}$ & $\begin{array}{l}\text { Qualitative } \\
\text { nominal } \\
\text { Politics }\end{array}$ & $\begin{array}{l}\text { Known } \\
\text {-Know little } \\
\text {-Do not know }\end{array}$ & $\begin{array}{l}\text { If you answer more than } 50 \% \text { of the items If you } \\
\text { answer less than } 50 \% \text { of the Items. If you answer: } \\
\text { only } 20 \% \text { of the items }\end{array}$ \\
\hline
\end{tabular}

\section{Procedures}

Blood samples were taken for fasting glycaemia. The degree of metabolic control was determined according to 3 criteria, fasting glycaemia values lower than $9.1 \mathrm{mmol} / \mathrm{L}$ for controlled patients, admissible up to 9 and higher for uncontrolled patients. A group of interventions was applied as part of the study which was grouped into: educational and preventive Policy interventions. Group dynamics, individual interviews, conferences, monitoring and control

Participation of the multidisciplinary team and advised by the teaching staff of experience the educational program was given with 20 hours of duration during 5 weeks of work with a daily frequency of 4 hours where 2 facilitators participated at least, for the development of the same they were made 2 groups of 10 patients in each. The program lasted 9 weeks; to evaluate the same was applied, at the end, the same questionnaire shown in (Annex 2).

\section{Results}

Table 2 corresponds to 54\% Female sex prevalent not age $60-65$ years between s risk factors hipe raw blood rtensión $100 \%$. The $60 \%$ of older adults had an acceptable metabolic control, having these of 6 to 9 years of disease evolution.
I was taken into account for the design of these actions the parameters established to ensure patient safety, given that these actions must be performed $\mathrm{s}$ the same patient himself so previously tested this program in a pilot group responded satisfactorily these actions.

\section{Ethical Aspects}

All patients were informed that it would be very useful for the investigation to know some aspects related to their degree of general information about Diabetes Mellitus (DM) and that the information derived from this study would be used to improve the explanations that they and other diabetic patients would receive to prevent future complications. After receiving this information, cooperation was requested for the interview and it was emphasized that they had full freedom to accept or not. During the interview, extreme care was taken not to use any question or phrase that might suggest responsibility or fault on the part of the patient or the health personnel who attended him.

When analyzing the Table 3 it is observed that $45 \%$ of the studied older adults did not have knowledge about diabetes before the intervention, after the intervention, $70 \%$ of this knowledge was satisfactorily reversed. ${ }^{6,7}$ 
Table 2 General Characteristics of the Studied Sample

\begin{tabular}{|c|c|c|c|}
\hline Variable & & $\#$ & $\%$ \\
\hline \multirow[t]{2}{*}{ Sex } & Female & Eleven & 55 \\
\hline & Male & 9 & Four. Five \\
\hline \multirow[t]{3}{*}{ Ages groups } & $60 \_65$ & Eleven & 55 \\
\hline & 66_70 & 6 & 30 \\
\hline & 70 more & 3 & Fifteen \\
\hline \multirow{7}{*}{$\begin{array}{l}\text { Time of evolution } \\
\text { of the disease }\end{array}$} & Suitable & 6 & 30 \\
\hline & Admissible & 5 & 25 \\
\hline & Inadequate & 9 & Four. Five \\
\hline & _l year & 1 & 5 \\
\hline & I_5 & 4 & Twenty \\
\hline & $6 \_10$ & 9 & Four. Five \\
\hline & More 10 & 6 & 30 \\
\hline \multirow[t]{7}{*}{ Risk factor's } & H.ta & Twenty & 100 \\
\hline & Overweight & 12 & 60 \\
\hline & Obesity & 7 & 35 \\
\hline & Mpp & 7 & 35 \\
\hline & Sedentarism & 7 & 35 \\
\hline & Smokers & 13 & 65 \\
\hline & $\begin{array}{l}\text { Intake alcoholic } \\
\text { beverages }\end{array}$ & 9 & Four. Five \\
\hline
\end{tabular}

Source Clinical history

Table 3 Knowledge about diabetes education in type 2 diabetic older adults

\begin{tabular}{lllll}
\hline \multirow{2}{*}{ Knowledge } & \multicolumn{2}{l}{ Before the intervention } & \multicolumn{2}{l}{$\begin{array}{l}\text { After the } \\
\text { intervention }\end{array}$} \\
\cline { 2 - 5 } & $\#$ & $\%$ & $\#$ & $\%$ \\
\hline Known & 5 & 25 & 14 & 70 \\
Know little & 6 & 30 & 6 & 30 \\
Do not know & 9 & Four. Five & - & - \\
Total & twenty & 100 & twenty & 100 \\
\hline
\end{tabular}

Source survey

\section{Discussion}

In the analysis of the data 1 This work was revealed that most patients who took part in 1 study were above 60 years of age, female gender has been recognized and it has a direct relationship with the frequency of women affected by DM. ${ }^{8}$ It is also clear that over 60 years of age is an increased risk of diabetes, type 2 DM essentially; it was evidenced that the greater\% correspond to the female sex and in over 60, coinciding with Ibáñez Esquembre that raises that women over 60 diabetic are the most affected by this disease, being this in relation to what was found in most of the Countries in which the prevalence of diabetes is higher in women than in men, which means that after the age of 40 , women have decreased the functional capacity of the ovaries ${ }^{9}$ which is why this constitutes a risk group to take into consideration in terms of prevention

Metabolic control is an important indicator of the diabetic patient so diabetological education directly affects this parameter with these people therefore in their future evolution, so that a person with diabetes is considered controlled is necessary to maintain adequate levels of glycaemia according to research are those that have demonstrated a significant decrease in the risk of chronic complications. ${ }^{10}$ In the research, metabolic control is admissible There are authors who state that self-control and self-care is essential to evaluate the metabolic state of the disease, it will not replace periodic medical check-ups to which the patient must go and in which will be assessed by the doctor. Metabolic control is an important indicator of the diabetic patient so education diabetológica directly affects this parameter with these people therefore in their future evolution. ${ }^{10}$ For a person with diabetes to be considered controlled, it is necessary to maintain adequate levels of glycaemia, ${ }^{11}$ according medical research is sometimes not possible to obtain the best figures in the elderly should be evaluated for risk benefit; For example, in the 70-year-old, aspirin should not be expected to have the same blood glucose levels as in a 20 -yearold, because although hypoglycaemia should be avoided at any age, it is essential to minimize the possible risks of these people over 60 years of age due to its negative impact on the nervous system, which depends primarily on glucose for its functioning. According to Rosario García in research done only people with diabetes educated in their ailment will be those who achieve a good metabolic control, they will have a lower risk of developing complications and therefore they will live longer and with a better quality of life. ${ }^{12}$

International studies have been carried out, in which it was determined that complications occur after 12 years of evolution of diabetes. In the present study it was observed that the highest $\%$ corresponds to patients of 6-9 years of evolution of diabetes. Disease coinciding with previous studies that suggest that the time of evolution of the disease have a higher risk of suffering from chronic complications. The time of evolution of DM is considered a risk factor for Diabetic Macroangiopathy in Lower Members (MDMI), therefore it will always be important to take it into account in the management of this disease. The fact that the time of evolution of the disease is not significantly associated from the statistical point of view lacks a logical argument, since the evolution of the disease increases the frequency of chronic complications of Diabetes. ${ }^{13}$

Recent research shows that there is an association between high blood pressure and the onset of type 2 diabetes for any sex. It has been verified and ratified that among type 2 Diabetic patients, there is hypertension, dyslipidemia, ischemia cardiopathy, having a very high prevalence among the population of diabetics, in various epidemiological studies it has been proven that approximately between $40 \%$ and $60 \%$ of diabetics suffer from hypertension. ${ }^{14}$ It was shown here that the greatest number of patients suffered from hypertension. The early detection of this disease guarantees a better quality of life for these patients; the results expressed here show once again the importance of the correct education of diabetic patients in terms of disease control and other associated entities

L HTA is crucial in the development and progression of diabetic nephropathy, it is having further shown that an appropriate treatment of hypertension can slow the progression of said nephropathy ${ }^{15}$ and another because hypertension is one of the most important factors of risk the development of cardiovascular and cerebrovascular complications, especially in type 2 diabetics. ${ }^{16}$ 
According to the report of the group of studies for the prevention of Diabetes Mellitus diabetic education is defined as the fundamental activity, this has been to inform and train the patient from the fundamental points of their disease, being demonstrated the importance of planning and teaching educational programs to these patients. In the present study it was evidenced that the patients had no knowledge of diabetes before the intervention, so they assume risk behaviours due to lack of education. There are authors who raise the insufficiency of knowledge about the disease and its care, which shows a deficiency of them and a low perception of self-care as the main tool in the well-being of their health. ${ }^{17-21}$

\section{Acknowledgements}

None.

\section{Conflict of interest}

Author declares that there are no conflicts of interest.

\section{References}

1. Yudit HE, María CVV, Rosa EGJ, et al. Diabetes mellitus and psychological depression in the elderly. Rev Hosp Psychiatric Hospital of Havana. 2012:9(3).

2. Alvarez CJT, Bello HV, Pérez HGlA, et al. Coronary risk factors associated with acute myocardial infarction in the elderly. MEDISAN. 2013;17(1):54-60.

3. Mozaffarian D, Kamineni A, Carnethon M, et al. Risk factors in older adults with diabetes mellitus. MEDISAN. 2012;16(4):489-497.

4. Manrique EB, Salinas RA, Moreno TKM, et al. Health conditions and functional status of older adults in Mexico. Public Health Mexico. 2015;55(Supp12):S323-S331.

5. Jordán ST, Oramas GR, González CL. Evaluation of the effect of an educational intervention in diabetic patients from four offices. Rev Cubana Med Gen Integr. 2007;23(2).

6. Díaz DO, Licea PM, Bostillo SE, et al. Diabetes Mellitus Some aspects of interest. Havana: ECIMED. 1986:30-58.

7. Faget CO. Diabetes Mellitus, a health problem. Avances Méd de Cuba. 2000;(23):19-13.
8. Domínguez BS, Cortina MI, Bello RB. Educational intervention in diabetic patients in the parish of Valle de Tucutunemo Year 2004. Rev méd electron. 2008;30(2).

9. Ibáñez EV. New and necessary "forms" and tools for the comprehensive care of diabetics: from primary care to specialties center. Rev Anal Cir Card Vasc. 2003:9(2):122-128.

10. Carolino IDR, Molena FCA, Tasca RS, et al. Risk factors in patients with type 2 diabetes mellitus. Rev Latino-am Enfermagem. 2008;16 (2):238244.

11. Brenes CG, Rosero BL. Diabetes mellitus in older adults Costa Ricans. Rev Med. 2007;5(1).

12. García R, Suárez R. Education, the weakest point of comprehensive care of the diabetic patient. Surveillance technical report. 1997;2(6).

13. Aragón SFJ, Ortiz RPP. The diabetic foot Barcelona: Masson;2002:1-83.

14. Pérez DA, Alonso CL, García MAJ, et al. Educational intervention in type 2 diabetics. Rev Cubana Med Gen Integr. 2009;25(4).

15. Calderón J, Solis J, Castillo O, et al. Effect of education on the metabolic control of patients with type 2 diabetes mellitus at the Hospital Nacional Arzobispo Loayza. Rev Soc Perú Med Interna. 2003;16(1):17-25.

16. Yanes QM, Cruz HJ, Yanes QMA, et al. Diabetes mellitus in the elderly, a frequent problem. Cuban Rev Med Gen Integr. 2009;25(2).

17. Pérez CMD, Dueñas HA, Alfonso GJ, et al. Cuban guide for the prevention, diagnosis and treatment of arterial hypertension. Havana: ECIMED. 2006

18. Jordán ST, Oramas GR, González CL. Evaluation of the effect of an educational intervention in diabetic patients from four clinics. Rev Cubana Med Gen Integr. 2015;23(2).

19. Pan American Health Organization. Education about diabetes: let's reduce the cost of ignorance. DC: PAHO, Washington. 1996.

20. National Program of Chronic Diseases. Department of Preventive Medicine, Adult Health Section. Costa Rican social security box. Diabetes How to inject your insulin? San Jose Costa Rica: CCSS sf.

21. García R, Suárez R, Mateo AO. Communication and interactive education in health and its application to control of the diabetic patient. Rev Panam Public Health. 1997;2(1):32-36. 